Supplement of Atmos. Meas. Tech., 13, 2733-2749, 2020

https://doi.org/10.5194/amt-13-2733-2020-supplement

(C) Author(s) 2020. This work is distributed under

the Creative Commons Attribution 4.0 License.

(c) (1)
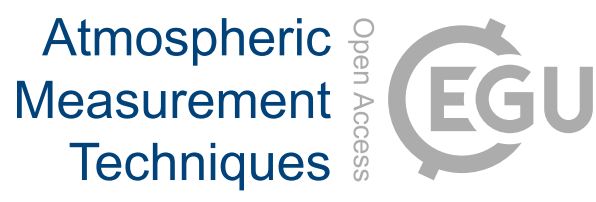

Supplement of

\title{
Model-based climatology of diurnal variability in stratospheric ozone as a data analysis tool
}

Stacey M. Frith et al.

Correspondence to: Stacey M. Frith (stacey.frith@nasa.gov)

The copyright of individual parts of the supplement might differ from the CC BY 4.0 License. 
Supplemental Figures 

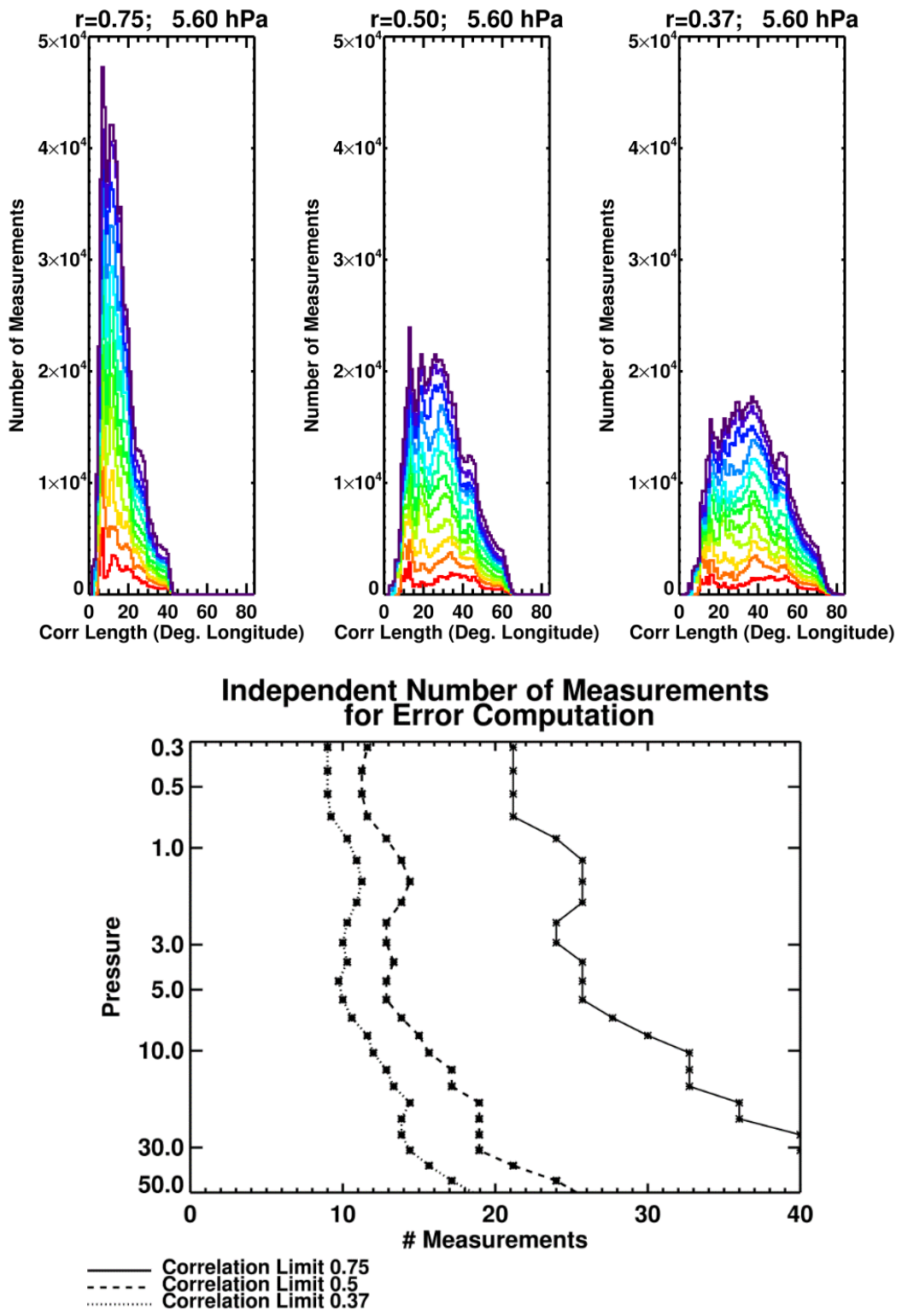

Figure S1. Top: Distribution of "correlation length" in degrees longitude, based on longitudinally-lagged correlations at each

5 model grid point. The correlation length is the lag (in degrees longitude) at which the correlation drops below the threshold. We compared threshold correlations of 0.75 (left panel), 0.5 (center panel), and 0.37 (right panel). Correlations are computed for the $15^{\text {th }}$ day of each month in order to sample at different seasons. Different colors show the distributions for successive months.

Bottom: The median of the distributions for each correlation threshold, plotted as a function of pressure, converted to number of independent measurements (corr. length $/ 360)$. Based on this we assume 12 independent measurements $\left(30^{\circ}\right.$ longitudinal sampling)

10 at all levels each day. Thus, we use $12 * 60$ days=720 independent measurements for computing standard error of the mean. 

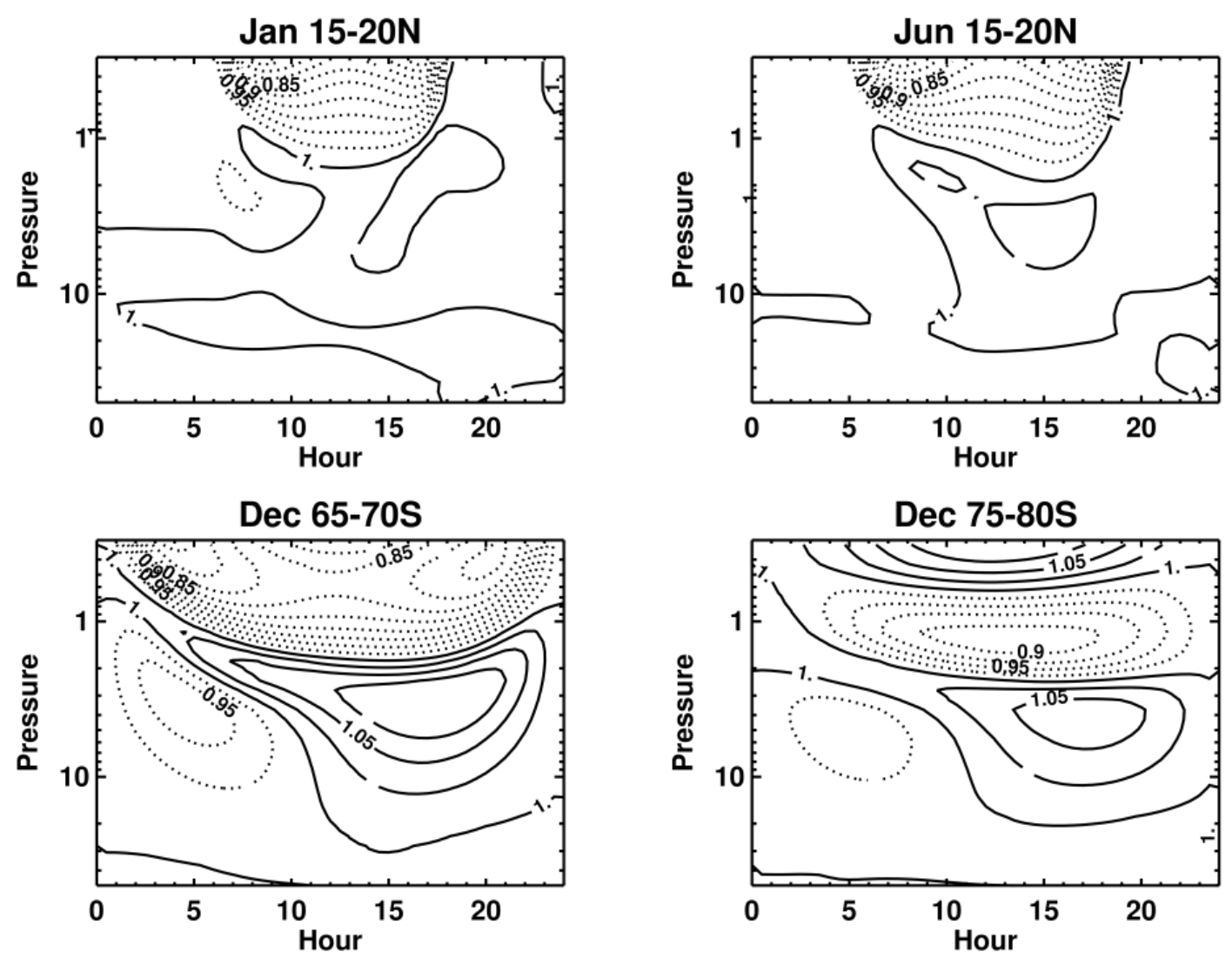

Figure S2. Same as Figure 1 but for January $15-20^{\circ} \mathrm{N}$ (top left); June $15-20^{\circ} \mathrm{N}$ (top right); December 65-70 $^{\circ} \mathrm{South}(\mathrm{bottom}$ left); and December $75-80^{\circ} \mathrm{S}$ (bottom right). The top two panels are directly comparable to the diurnal cycle in Parish et al. [2014]. The bottom panels show the hemispheric symmetry of the polar summer signal as compared to the June Northern Hemisphere results shown in Figure 1. 

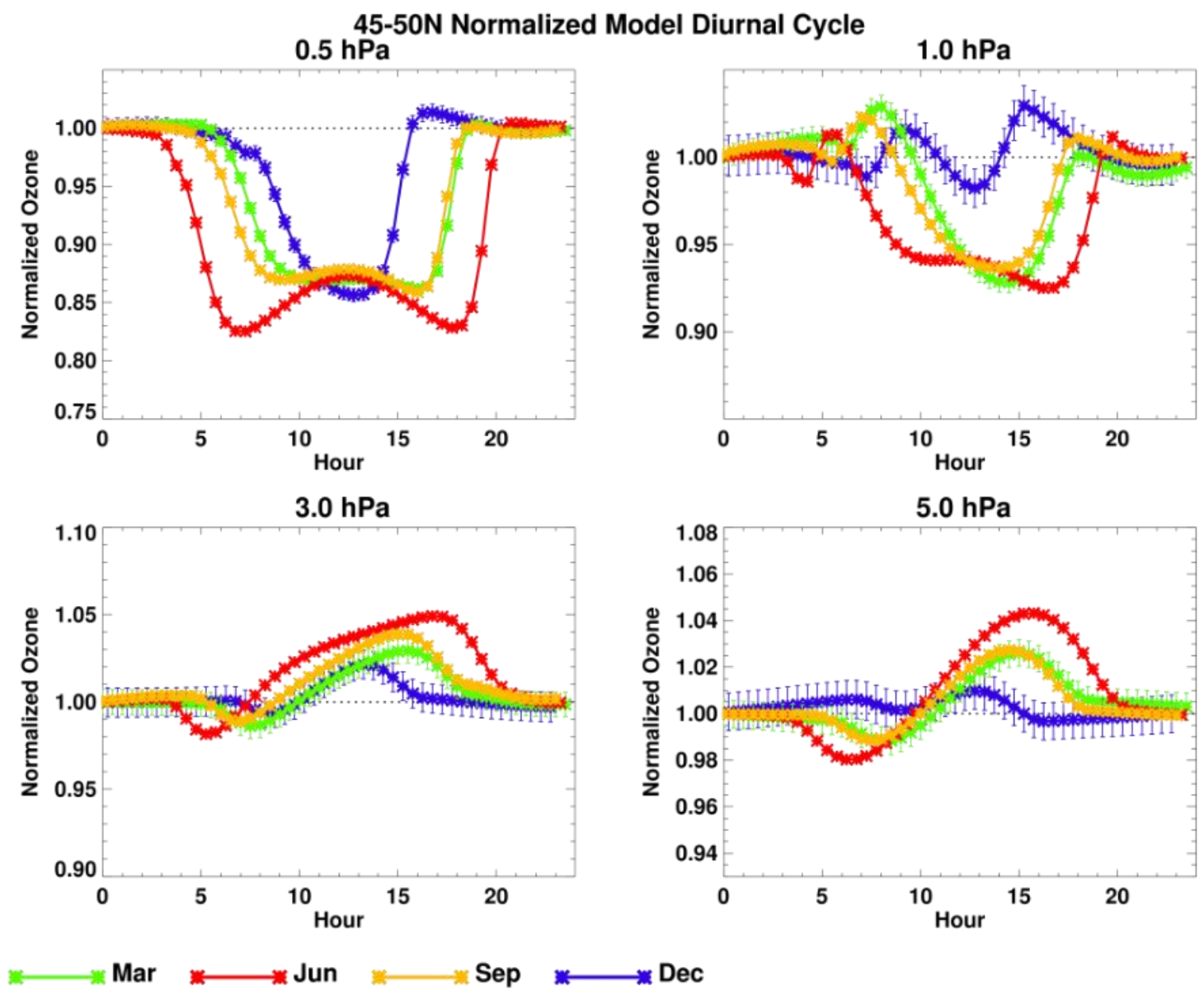

Figure S3. Same as Figure 2 but for $45-50^{\circ} \mathrm{N}$. The $5 \mathrm{hPa}$ result (bottom right panel) is directly comparable to Schanz et al. [2014; Figure 2]. 

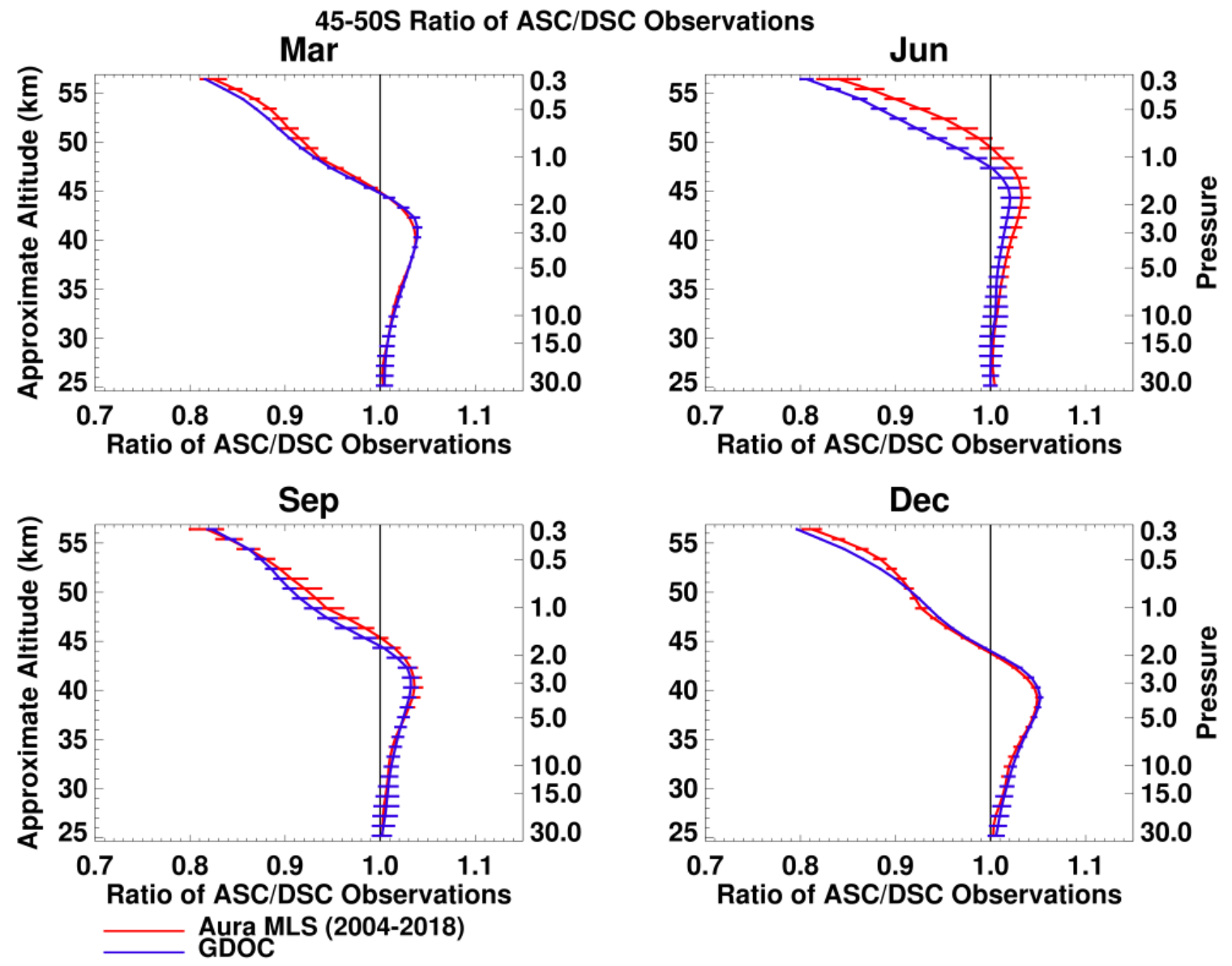

Figure S4. Same as Figure 6 but for $45-50^{\circ} \mathrm{S}$. 

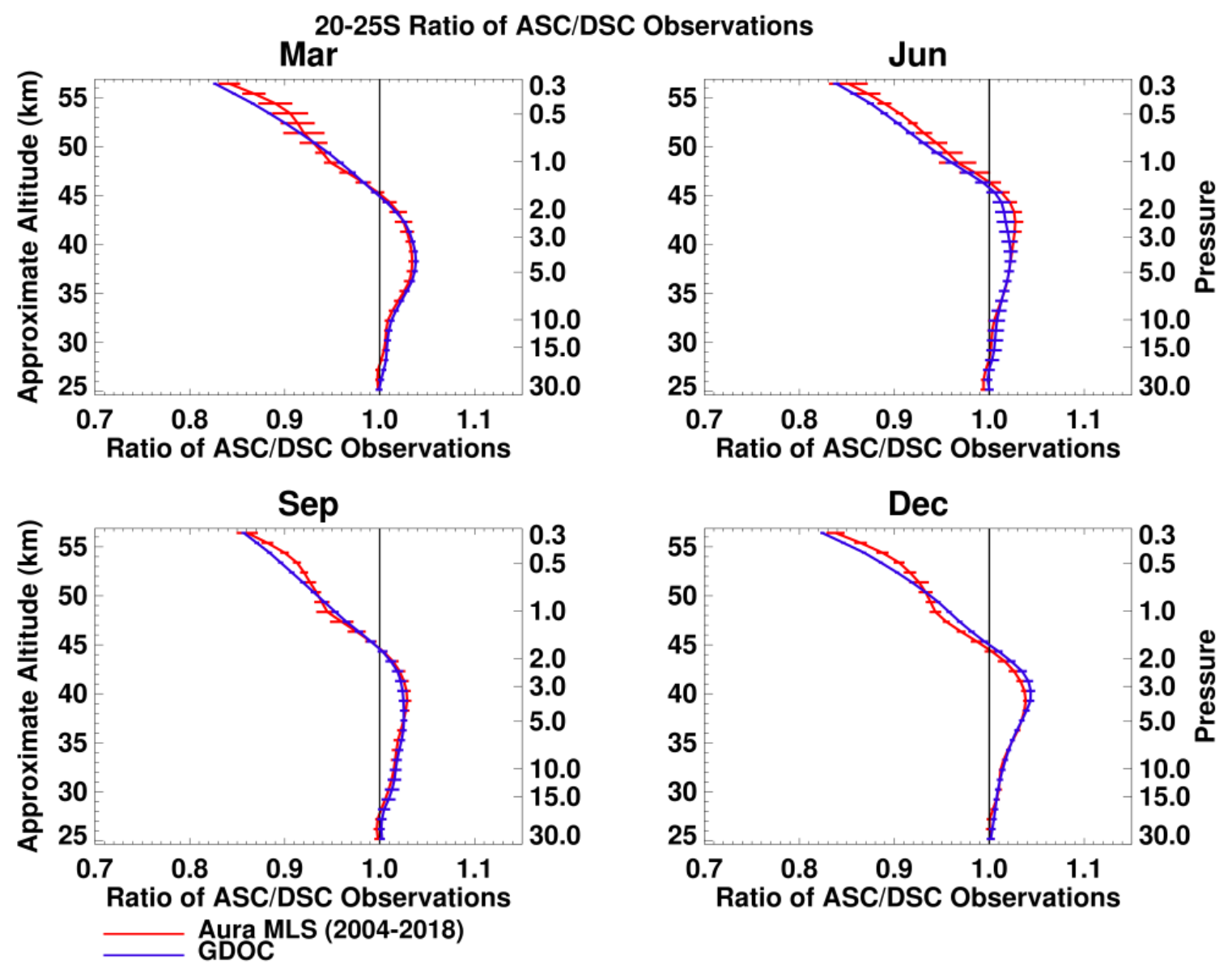

Figure S5. Same as Figure 6 but for $20-25^{\circ} \mathrm{S}$. 

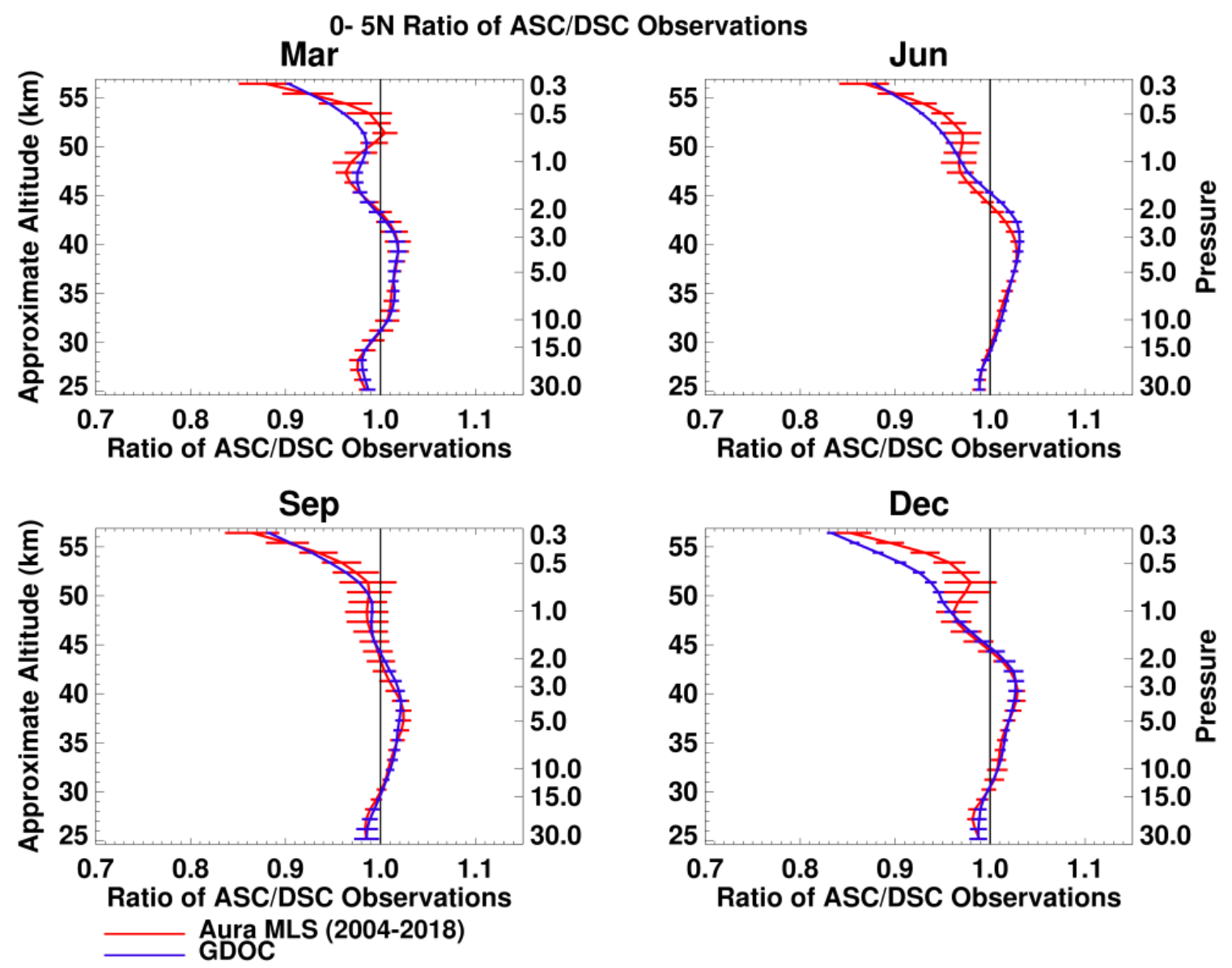

Ratio of ASC/DSC Observations

Figure S6. Same as Figure 6 but for $0-5^{\circ} \mathbf{N}$. 

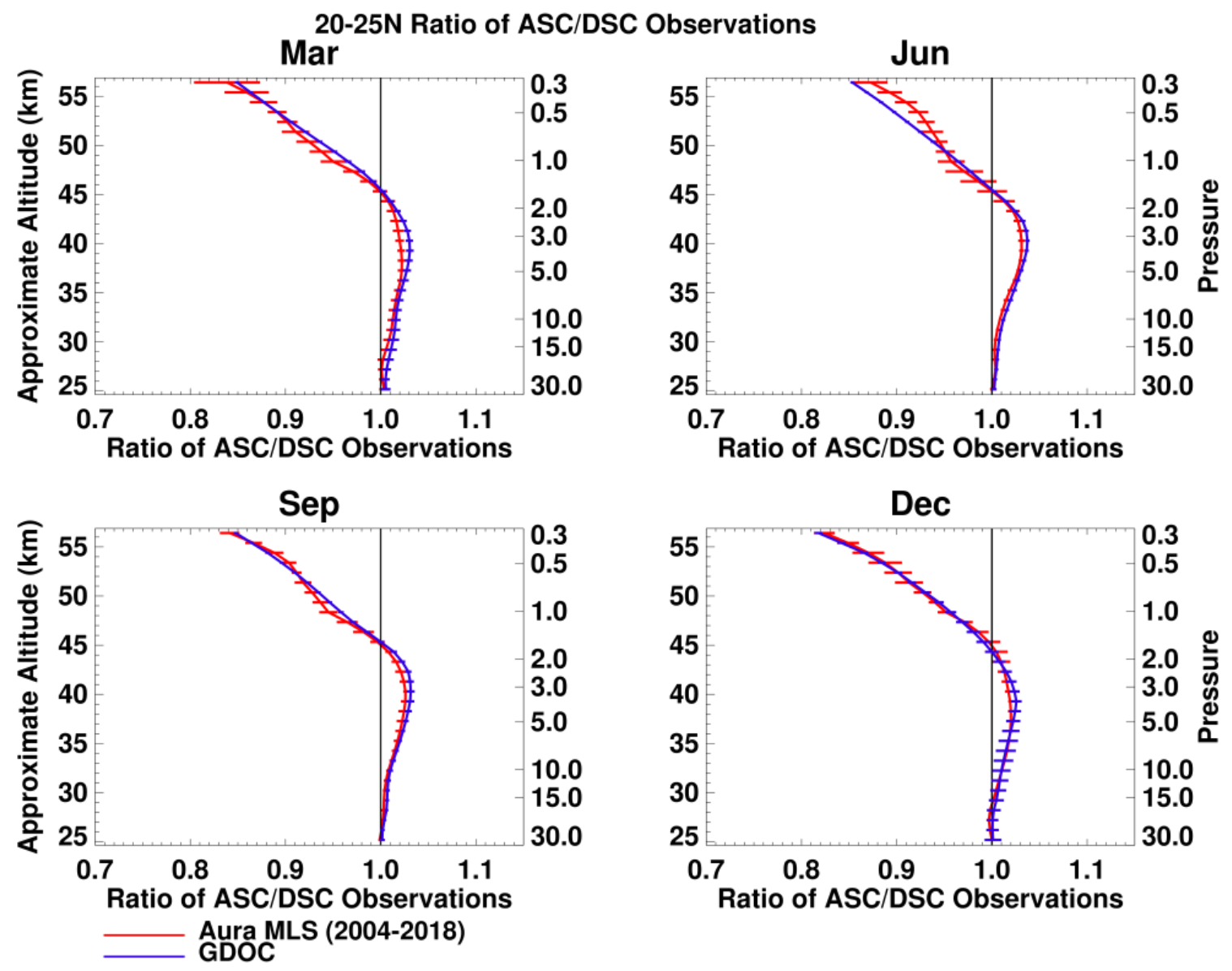

Figure S7. Same as Figure 6 but for $20-25^{\circ} \mathrm{N}$. 

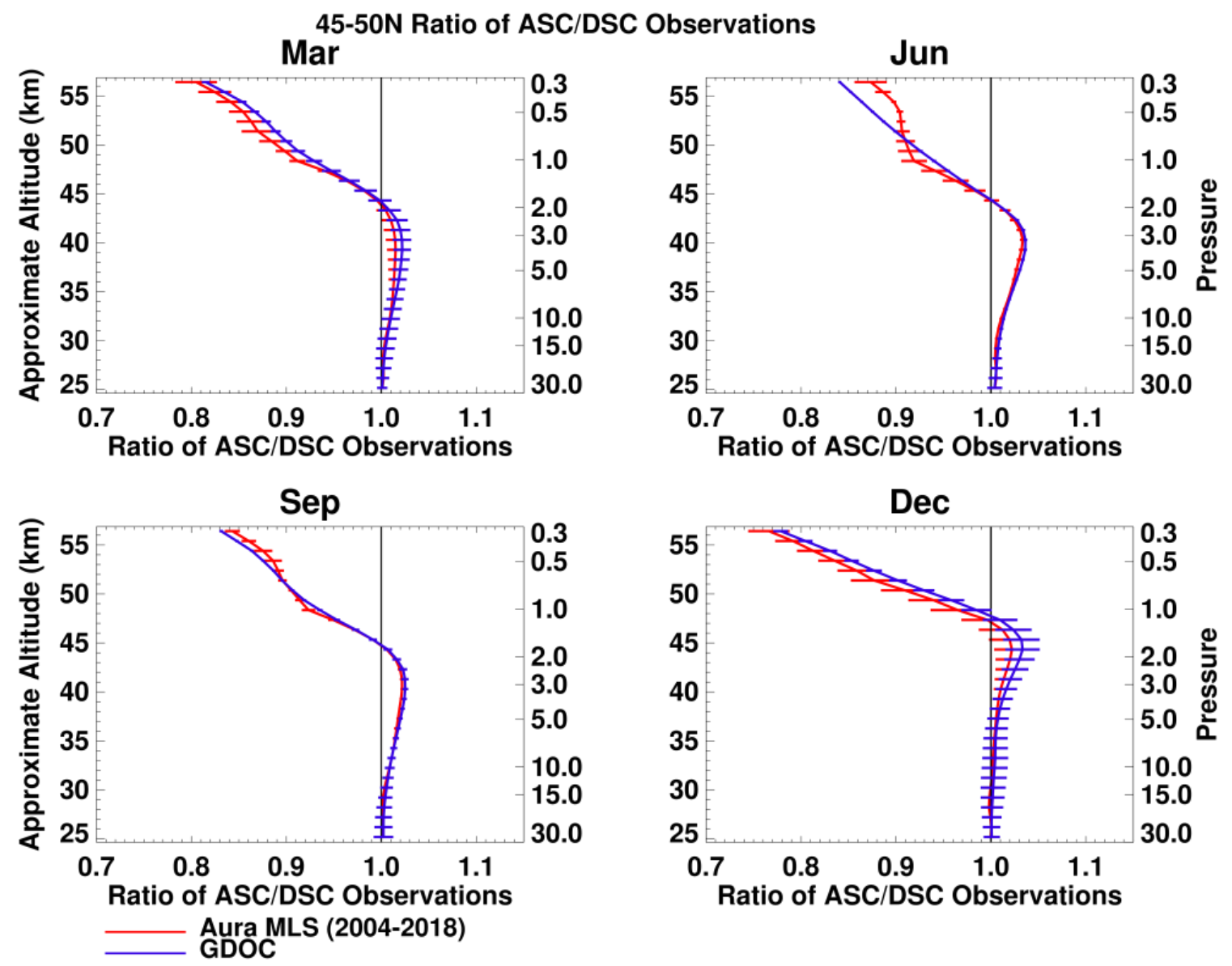

Figure S8. Same as Figure 6 but for $45-50^{\circ} \mathrm{N}$. 

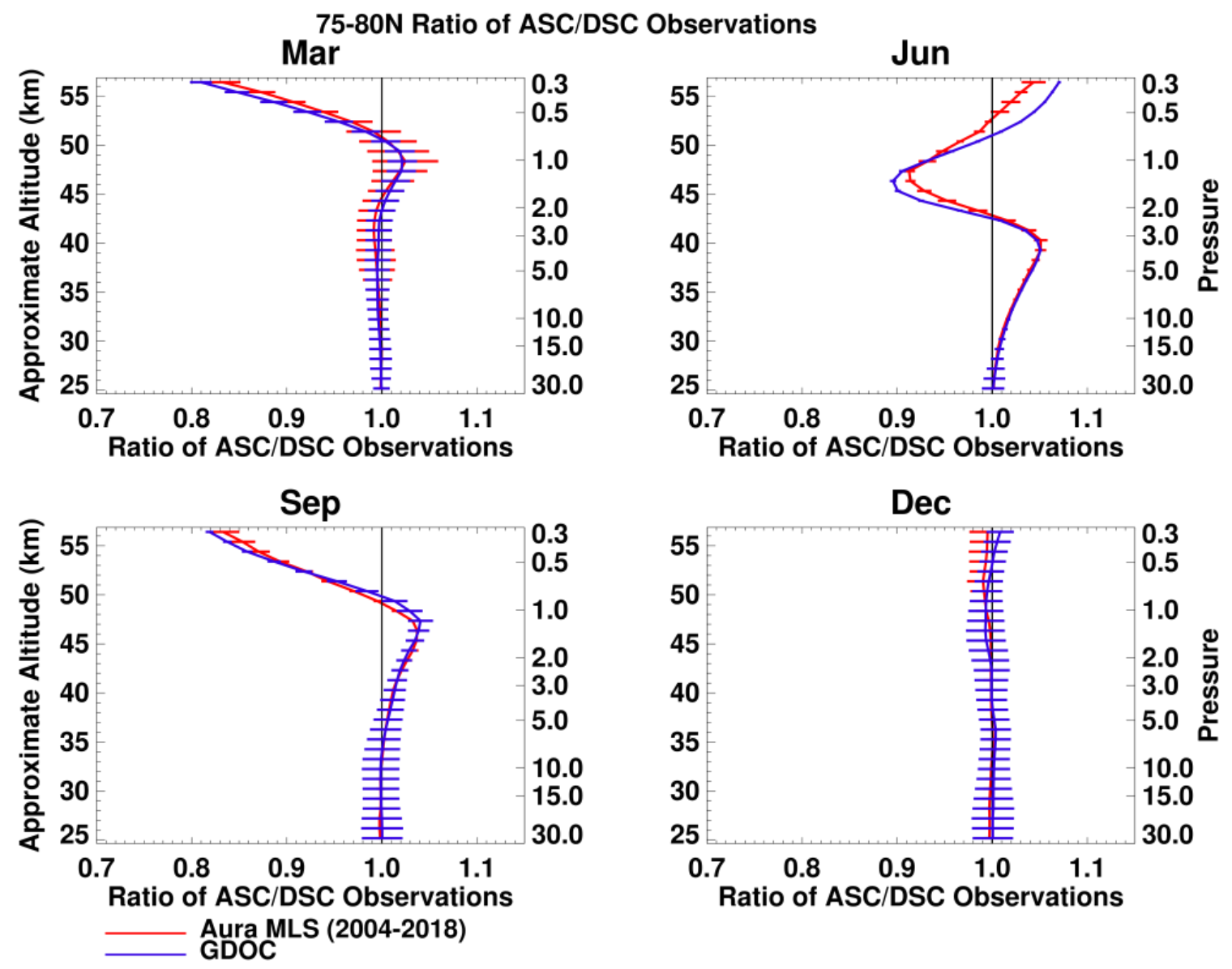

Figure S9. Same as Figure 6 but for $75-80^{\circ} \mathrm{N}$. 

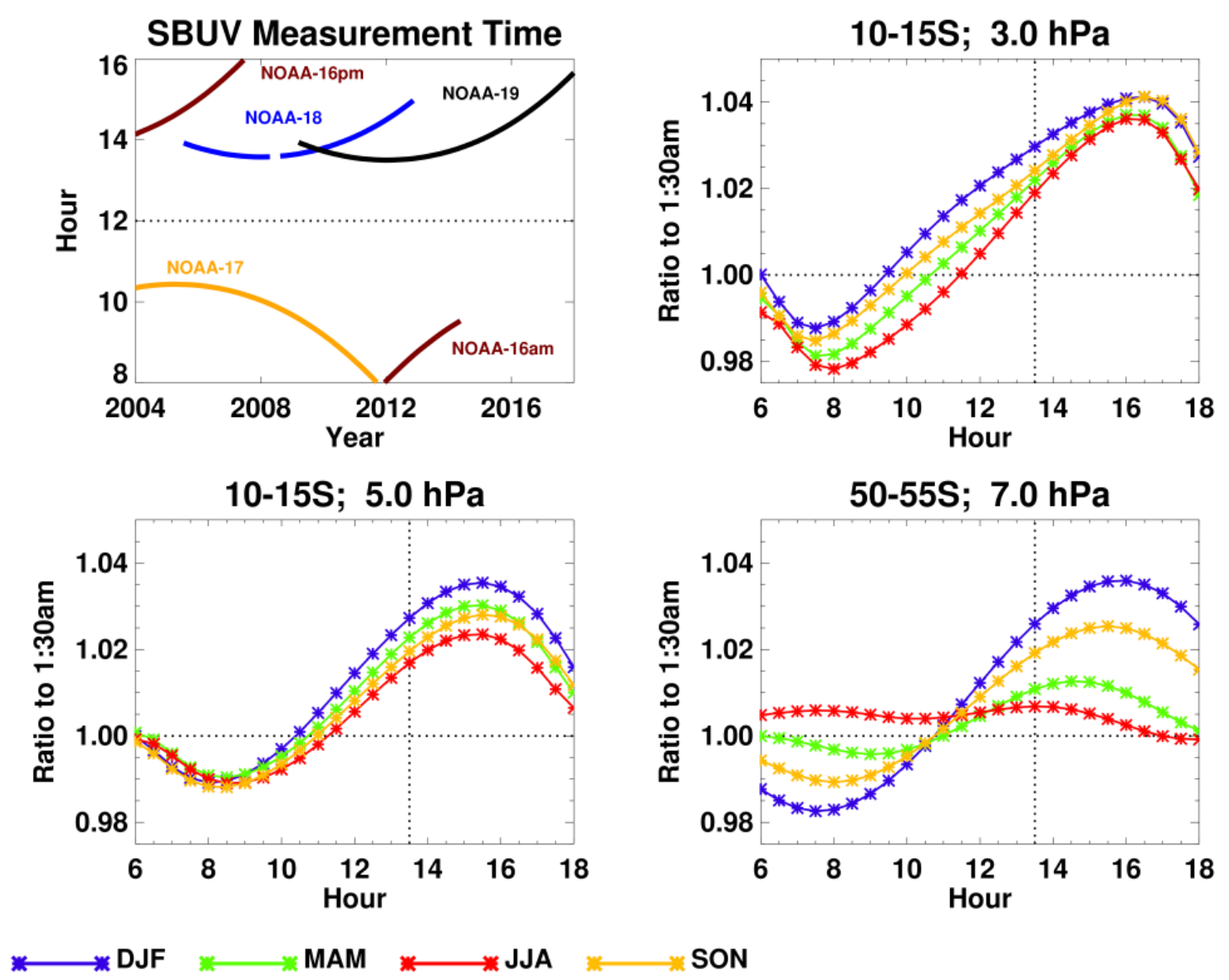

Figure S10. GEOS-GMI diurnal climatology (GDOC) as a function of month for the latitude range and pressure level of the SBUV time series comparisons relative to Aura MLS in Figures 9 to 11. The first panel shows the slow drift of the SBUV measurement

5 local solar time as a result of satellite orbit drift. Measurements are taken primarily in the 2 to 4 pm time range and 8 to 10 am time range. In the upper right panel $\left(10-15^{\circ} \mathrm{S} ; 3 \mathrm{hPa}\right)$ there is an offset between the morning and afternoon measurements as well as a gradient from 8 to $10 \mathrm{am}$ and 2 to $4 \mathrm{pm}$, which translates to a diurnally-induced drift in the SBUV time series. In the lower left panel $\left(10-15^{\circ} \mathrm{S} ; 5 \mathrm{hPa}\right)$ there is little variation between 8 to $10 \mathrm{am}$ and 2 to $4 \mathrm{pm}$, but only an offset between the morning and afternoon measurements. Finally, in the bottom right panel $\left(50-55^{\circ} \mathrm{S} ; 7 \mathrm{hPa}\right)$ there is little diurnal cycle in winter (JJA) but a strong diurnal cycle in summer (DJF), which imparts a diurnally-induced seasonal-scale variation in the SBUV record. Vertical dotted line indicates 1:30pm Aura MLS measurement time for reference. 

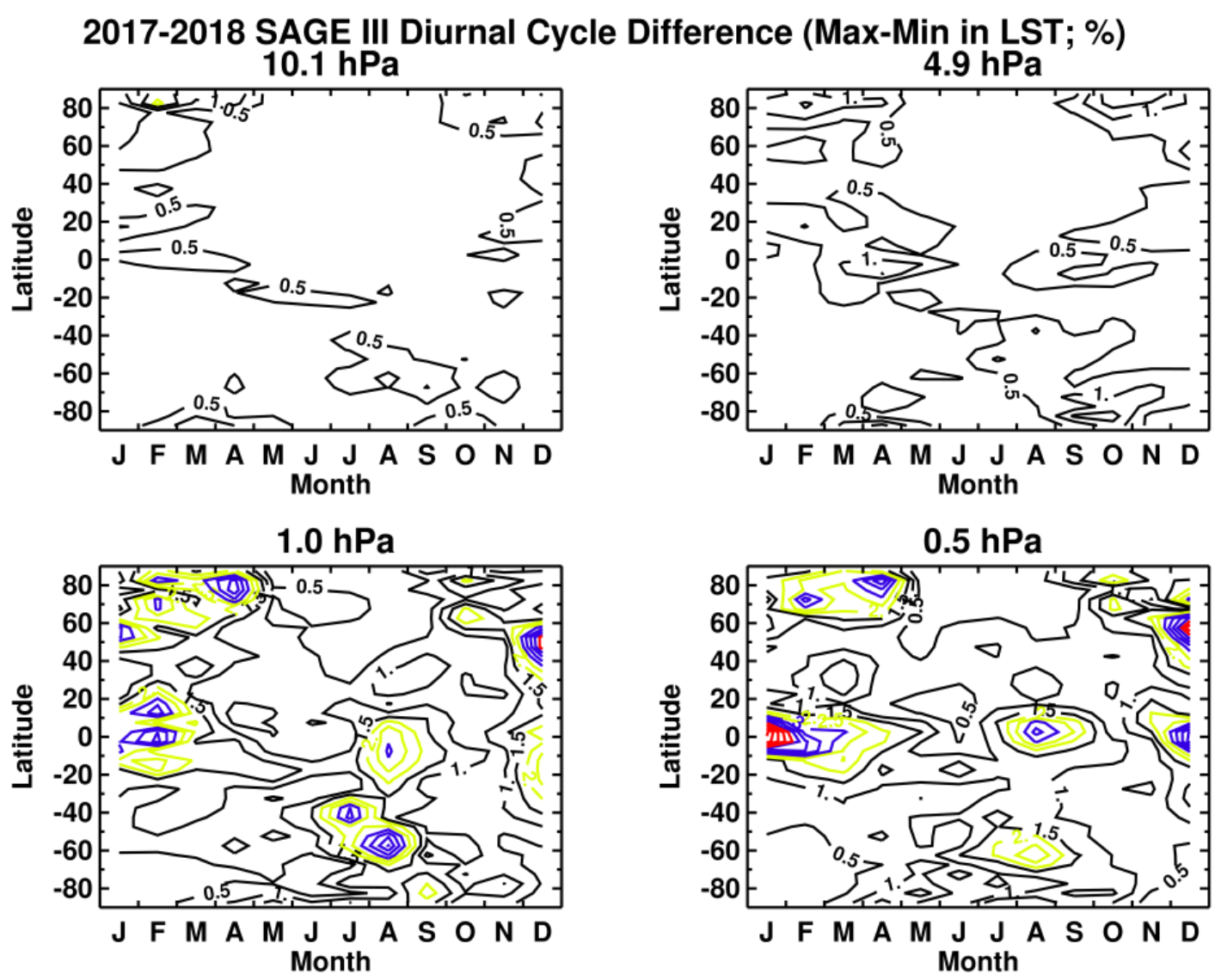

Figure S11. Contour plot of the differences between the diurnal climatology computed from 2017 output and from 2018 output. Differences are expressed as the amplitude of the max-min differences in local solar time and provide information on interannual variability in the model diurnal signal. Contour intervals are $0.5(5 \%)$. Variations of $2 \%$ or greater are colored in yellow, $3 \%$ or greater in blue, and greater than $5 \%$ in red. Below $5 \mathrm{hPa}$ the differences are generally less than 1\%. At higher levels there are sporadic instances of larger differences (3-5\%) in the tropics (also seen in Figure S10) and at higher latitudes. As more years of model output become available, we will be able to better characterize interannual variability in the model. 

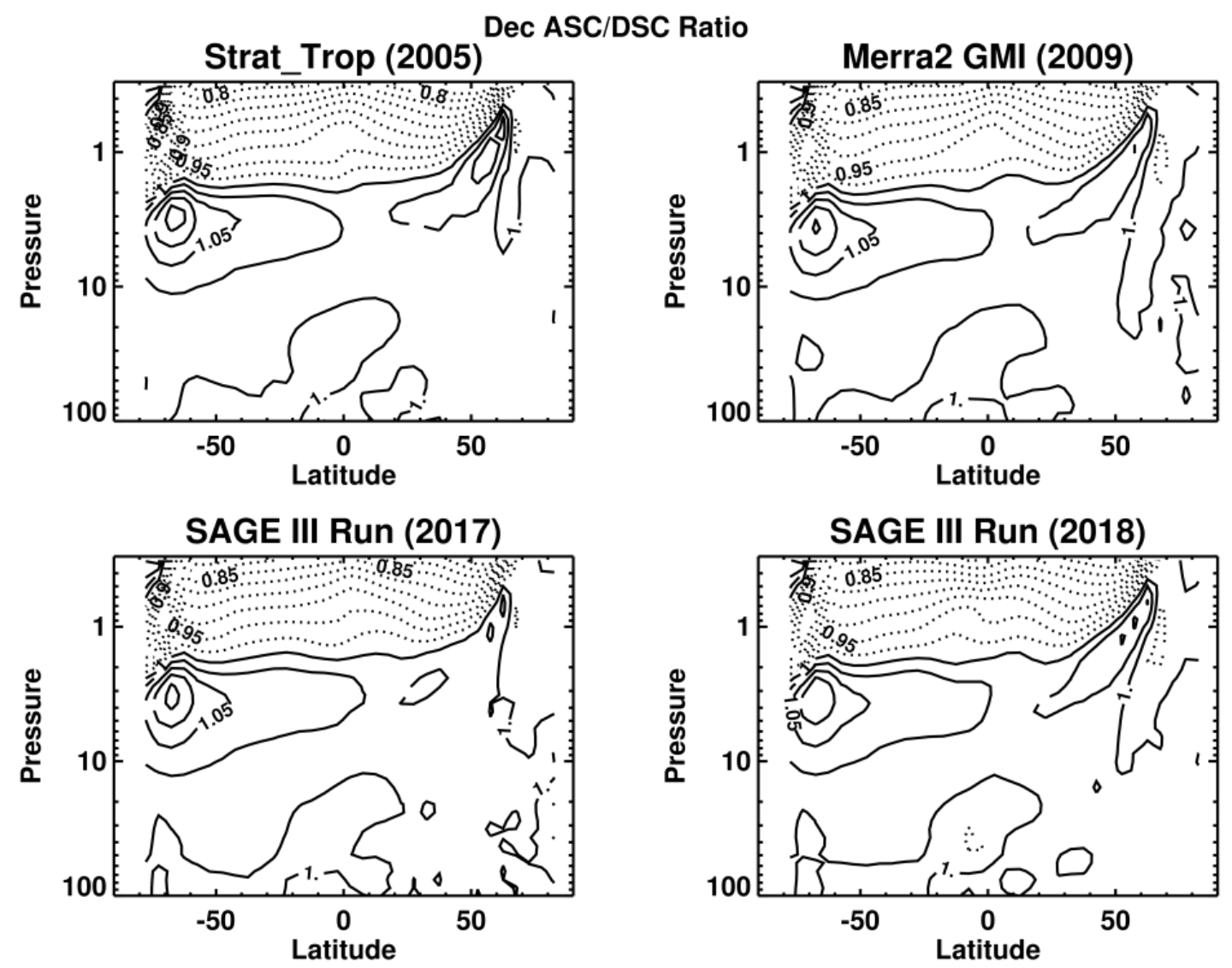

Figure S12. Contour plot of diurnal climatology as derived from four model realizations. The ratio of the day to night values corresponding to Aura MLS measurement times are shown with a ratio contour interval of $.025(2.5 \%)$. The day to night ratio of ozone is similar in all models, despite a number of model modifications and different year simulations. We note that the GEOSCCM simulation used in Parrish et al. [2014] is included here (Strat_Trop 2005) only to demonstrate that model improvements have not drastically changed the model diurnal signal, but that this particular simulation is outdated. The final climatology is the average of outputs from the SAGE III 2017 and 2018 model runs. 